\title{
INVESTIGAÇÃO DOS FATORES RELATIVOS À REINTERNAÇÃO DO JOVEM EM CONFLITO COM A LEI
}

\author{
INVESTIGATING THE FACTORS RELATED TO \\ RE-INSTITUCIONALIZACION OF TEENAGER \\ CONFLICT WITH THE LAW
}

\author{
Érico Douglas Vieira ${ }^{1}$, Camila Fin ${ }^{2}$ e Silmara Silva Cardoso ${ }^{3}$
}

Recebido em: 24/02/2012

Aprovado em: 03/10/2012

\section{RESUMO}

O presente trabalho é um relato de uma pesquisa qualitativa, realizada com adolescentes em conflito com a lei. Foram entrevistados sete adolescentes que cumpriam medida socioeducativa de privação de liberdade. O objetivo era compreender os fatores envolvidos na reinternação, a partir do ponto de vista dos próprios adolescentes. Nestes casos estudados, observou-se que a família não representa fator de risco, ao contrário da convivência com o grupo de amigos. $\mathrm{O}$ cumprimento da medida apresenta um caráter repressivo e punitivo em vez do pretendido caráter educativo, promulgado pelo ECA. Os adolescentes colocam o futuro sob duas óticas contrárias: ora como possibilidade de reinvenção da identidade, longe dos atos infracionais; ora como ausência de perspectivas de renda e trabalhos dignos.

Palavras-chave: Adolescentes; Atos infracionais; Medida socioeducativa.

\section{Introdução}

Este trabalho tem como objetivo pesquisar as questões envolvidas na reincidência do adolescente em conflito com a lei na cidade de Jataí-GO. O adolescente que comete atos infracionais configura-se como importante tema atual. Percebe-se que existe, no imaginário social, uma responsabilização desses jovens pelo aumento da violên-

\begin{abstract}
This paper reports a qualitative study conducted with adolescents in conflict with the law. Seven teenagers were interviewed in custody homes. The aim was to understand the factors involved in re-institutionalization from the perspective of adolescents themselves. In these cases studied, it was observed that the family does not represent a risk factor, as opposed to living with a group of friends. Enforcement of the sanction has a punitive and repressive character instead of the desired character education promulgated by the ECA. Teenagers put the future in two different contrary: sometimes as a possible reinvention of identity away from illegal acts either as the absence of prospects for decent jobs and income.
\end{abstract}

Keywords: Teenagers; Infractions; Socioeducational measure.

cia no país (CASTRO E GUARESCHI, 2008). Em São Paulo, a porcentagem de homicídios cometidos por adolescentes foi de $1 \%$ em relação ao total de homicídios cometidos no ano de 2006 (ROMAN, 2009). O que se percebe é um aumento do número de internações de adolescentes. No estado de Goiás, houve 108 internações no ano de 2008 e 147 internações no ano de 2009, representando um aumento de $36,10 \%$.

${ }^{1}$ Professor do curso de Psicologia da Universidade Federal de Goiás - Campus Jataí, Brasil. Psicólogo, Especialista em Psicodrama, Mestre em Psicologia, Doutorando em Psicologia pela Pontifícia Universidade Católica de Goiás, Brasil. E-mail ericopsi@yahoo.com.br.

${ }^{2}$ Psicóloga, Consultora em Psicologia Organizacional. E-mail: camila theend@hotmail.com.

${ }_{3}^{3}$ Psicóloga, Educadora Social do Programa Nacional de Inclusão de Jovens, Brasil. Psicóloga no CAPSi-Cirandar em João Pessoa -PB. Trabalha com jovens dependentes químicos. E-mail: silmarasilvago@gmail.com. 
As internações provisórias passaram de 54 em 2008 para 108 em 2009, perfazendo um aumento de $100 \%$. Goiás foi o segundo estado brasileiro com maior taxa de crescimento em internações provisórias. Há uma grande evolução das internações quando se analisa todo o território nacional. Em 1996, havia 4245 internações e, em 2009, o número chegou a 16940 internações no Brasil ${ }^{4}$.

A mídia e a sociedade apoiam a violência repressiva do Estado contra os adolescentes, como se estes fossem os autores dos crimes mais brutais. O Estado tem legitimidade e autorização para cometer violência e, até mesmo, para matar, como nos casos de países em que há a pena de morte. Em decorrência desse quadro, surge um clamor social que reivindica o aumento do poder repressivo do Estado, como, por exemplo, o rebaixamento da idade penal e o aumento de internações de adolescentes, como formas de combate ao problema. Importante questão se apresenta: até que ponto a justiça responde de forma acrítica a esse clamor social? Torna-se necessário uma análise mais profunda do tema, na medida em que o ato infracional pode ser o resultado de uma tentativa de reconhecimento social através da violência.

Não há um entendimento de que exista uma conexão entre o contexto social e os atos infracionais dos adolescentes. O foco é no indivíduo, fato que apaga a multiplicidade de relações que definem a marginalidade dos jovens (ROMAN, 2009). Esta é entendida como uma questão de escolha, restando ao Estado e à sociedade trazerem sofrimento e punição ao jovem que cometeu o equívoco. A violência deve ser compreendida como fato social e não individual somente. Segundo Roman (2009), há fortes correlações entre índices de homicídios e questões socioeconômicas: "quanto menor o IDH (Índice de Desenvolvimento Humano) de uma região, maior é seu índice de homicídios" ${ }^{4}$ Estes dados foram retirados do site http://www.ilanud.org.br/midia/doc/ Levantamento-Nacional-SINASE-2009-SDH-SNPDCA.PDF (p. 91). Não se quer dizer, com isso, que exista uma correlação direta entre pobreza e violência. Para além da renda, a exclusão e a injustiça podem contribuir para o aumento da violência.

Diante desse quadro, esta pesquisa tem como foco a compreensão e o estudo sobre a reinternação de jovens que cometeram atos infracionais, internos do CIAJ - Centro de Internação para Adolescentes de Jataí. O trabalho buscou entender os fatores que influenciam na reinternação, fato que faz com que o jovem volte a ter que cumprir a Medida Socioeducativa. Nos primeiros contatos dos pesquisadores com a instituição, alguns funcionários do CIAJ dentre eles, o diretor e a psicóloga que acompanha os adolescentes - passaram a informação de que existe um alto índice de reinternação entre os jovens que cumprem a Medida. Neste caso, o intuito é o de colher o ponto de vista dos adolescentes. O foco da pesquisa, portanto, são as interpretações dos próprios adolescentes a respeito dos fatores envolvidos na reinternação.

\section{As medidas socioeducativas e o Centro de Internação}

Para a compreensão deste trabalho, é importante se ter uma noção do funcionamento do CIAJ. Ressalta-se que esta caracterização não se pretende exaustiva, muitos aspectos da instituição não serão retratados. O objetivo aqui é o de fornecer uma visão geral para situar o leitor.

O Centro de Internação para Adolescentes de Jataí - CIAJ -, no município de Jataí, estado de Goiás, tem como competência receber adolescentes em conflito com a lei para cumprimento de Medida Socioeducativa de Internação e Medida de Internação Provisória. Esta tem duração de até 45 (quarenta e cinco) dias, e a Medida de Internação pode durar de 03 (três) meses a 03 (três) anos. As Medidas Socioeducativas têm como objetivo assegurar os direitos dos 
adolescentes em conflito com a lei que chegam a ser internados.

De acordo com o Regimento Interno da instituição, que se baseia no Estatuto da Criança e do Adolescente, o CIAJ tem como principal objetivo o resgate da situação de exclusão em que se encontra o adolescente (Regimento Interno, Art. $3^{\circ}$ ). A Medida Socioeducativa tem como diretrizes a busca de reinserção social, bem como a responsabilização e educação do adolescente. De acordo com o Artigo $11^{\circ}$, o adolescente recebe atendimentos relativos à alimentação, educação, saúde, às atividades esportivas e culturais. Além disso, a instituição fornece auxílio com relação à documentação e à qualificação profissional.

Neste ponto, uma importante questão deve ser levantada, que se refere à medida de internação. Em 1927, surge o primeiro Código de Menores, criando uma categoria menor, que se consolida no Brasil. Esse título foi ganhando uma conotação negativa ao longo do tempo, fazendo com que adolescentes das classes populares fossem vistos como estando em situação irregular (ROMAN, 2006). Mesmo com o Código de Menores de 1979, crianças e adolescentes pobres continuaram a serem vistos como problemas da área, ou do assistencialismo ou da segurança pública. $\mathrm{O}$ ECA - Estatuto da Criança e do Adolescente - surge em 1990 para mudar a visão do adolescente em situação irregular para uma visão de que as crianças e adolescentes devem ser protegidos, pela família, pela sociedade e pelo Estado, de quaisquer formas de violência. O que se vê, ainda hoje, é o predomínio de uma visão menorista, à medida que o Estado, além de punir os adolescentes, coloca-os sob sua tutela, seu controle e sua repressão (ROMAN, 2009). Roman (2009) discorre sobre as audiências de adolescentes em conflito com a lei e argumenta que nestas existem resquícios de práticas inquisitórias. $\mathrm{O}$ adolescente é pressionado a confessar, arrepender- se, e ainda leva uma "bronca" do juiz como forma de punição.

O ECA (1990) prevê a internação somente em casos excepcionais, devendo ser aplicada quando for cometido um ato infracional de séria ameaça ou violência, ou quando houver reiteração no cometimento de delitos graves. Além disso, o ECA (1990) estabelece que, enquanto o adolescente cumpre a medida, tem o direito de receber atendimentos psicológicos, escolarização e profissionalização (CASTRO E GUARESCHI, 2008). O ECA (1990) estabelece diretrizes para que os centros de internação de adolescentes se diferenciem de instituições carcerárias comuns porque atendem uma clientela em período peculiar de desenvolvimento. Essas instituições devem ser reguladas por um paradigma socioeducativo e não punitivo. No geral, o que se percebe é que persiste ainda o caráter prisional e repressor das intervenções junto ao jovem que comete ato infracional.

Roman (2009) aponta que existem roteiros de ações e representações para policiais e adolescentes que os ultrapassam historicamente como indivíduos e os colocam em condições opostas. Diz o autor: "(...) de um lado a polícia, instituição à qual se delega o monopólio de manter a ordem, ainda que por meio da violência; do outro o infrator, depositário ideológico do vício, desordem, da periculosidade ou da maldade doentia" (p. 98). Dessa forma, o Estado tem a autorização da sociedade para cometer violência contra estes "menores" supostamente perigosos. Geralmente, não se pergunta como é possível se defender da violência do Estado.

Talvez ainda predomine a lógica menorista, que vê o adolescente em conflito com a lei como questão de segurança pública e não como questão social. A segregação e o isolamento do adolescente talvez não almejem a intenção educativa, conforme apontam Castro e Guareschi (2008): 
É justamente este aniquilamento de qualquer forma de singularidade que a internação parece produzir nos adolescentes. Situação verificada pela própria linguagem dos funcionários das unidades de internação e repetida pelos adolescentes privados de liberdade ( p. 205).

A violação permanente da privacidade, a expropriação de atributos pessoais e as situações recorrentes de humilhação produzem a aniquilação da subjetividade, tornando problemático o propósito educativo. Como educar e ressocializar matando a singularidade?

\section{Os sofrimentos sociais e o ato infra- cional do adolescente}

A sociedade atual não enfatiza somente a "classe social", mas também o "lugar social" do indivíduo, ou seja, dá-se evidência também ao seu status, levando em consideração sempre o que ele possui de bens materiais (CARRETEIRO, 2003). Assim, a desigualdade social e o estímulo ao consumismo também podem ter sua parcela de responsabilidade ao fomentar atos infracionais como uma maneira do jovem conseguir a roupa da moda, por exemplo. Dessa forma, há uma busca de um enriquecimento de forma mais rápida e fácil, por vias ilegais, a fim de atingir o tão sonhado status social (SPAGNOL, 2005). Castro e Guareschi (2008), por outro lado, argumentam que a falta de bens materiais pode representar um fator de vulnerabilidade, e não uma causa, para cometimento de atos infracionais necessariamente. Percebe-se, então, que o ato infracional resulta de inúmeras lacunas e omissões tanto nas políticas sociais básicas, quanto na escola, no lazer, no Estado e na sociedade em geral, o que remete à responsabilidade de cada um de nós.

Carreteiro (2003) propõe a noção de sofrimento social ou sofrimento ético-político, como aquele experimen- tado por sujeitos em situações de humilhação, desvalorização e vergonha. Esses sujeitos, pertencentes a categorias subalternizadas, participam reiteradamente de dinâmicas sociais que invalidam e depreciam os seus códigos de conduta, deixando marcas profundas nas suas subjetividades. Tal quadro faz com que esses sujeitos sintam-se diminuídos e inadequados, levando-os a se perceberem como compondo o imaginário da inutilidade. Eles são condenados a não serem ouvidos pela maioria da população.

Carreteiro (2003) afirma que uma das conseqüências advindas da experiência das humilhações sociais é a utilização da lógica da virilidade. Os atos viris são executados como uma maneira dos jovens se firmarem como destemidos e corajosos, longe de humilhações e não reconhecimento por parte da sociedade. Agir com essa lógica seria agir de forma heroica, contra as injustiças já sofridas, como, por exemplo, a humilhação vivida pelos pais que é presenciada pelos filhos, os quais encontram, na violência, a única resposta para esse tipo de sofrimento. $\mathrm{O}$ olhar disciplinador por parte da sociedade observa as atitudes dos jovens a fim de detectar os comportamentos considerados desviantes e estes passam a ser identificados como indivíduos suspeitos e perigosos. Essa classificação também seria uma forma de humilhação, retirando o reconhecimento de seus códigos sociais e culturais, e principalmente colocando o jovem como inválido, gerando, assim, o sentimento de vergonha. Essa, por sua vez, é considerada como uma situação de inferioridade por parte daquele que é submetido a ela. Dessa maneira, a virilidade utilizada pelo jovem perante a vergonha vivenciada seria o seu modo reativo contra a repressão advinda daquele que o submete a essa situação.

Welzer-Lang (2001) propõe ideia semelhante, apontando que a questão da virilidade é imposta ao indivíduo ao longo de sua educação. Quando a crian- 
ça do sexo masculino tenta se firmar como homem, deixa de lado o mundo das mulheres, ou seja, para ser aceito no mundo dos homens, ele é obrigado a deixar de lado tudo que possa lhe associar às mulheres. $\mathrm{O}$ mundo dos homens é denominado pelo autor como "casa dos homens", caracterizada pelos lugares e espaços que o homem adulto ocupa para se firmar como verdadeiro homem. O período em que a criança está tentando se inserir na "casa dos homens" é apresentado como fase de homossociabilidade, na qual os mais velhos ditam o que é certo e o que é errado para que essa criança consiga atingir a virilidade. Muitas vezes, a orientação que a criança recebe acaba sendo feita com tapas, empurrões, ou, até mesmo, com socos e pontapés. Consequência possível dessa situação é a formação de indivíduos transgressores da lei, que compreendem que, para serem viris e respeitados, devem utilizar-se da violência.

De acordo com Spagnol (2005), os atos infracionais dos adolescentes também podem ocorrer sem motivações de posse, somente pela possibilidade de sentir alguma "emoção". Podem ser realizados de maneira cruel e não planejada, quando agem pela expectativa do momento do ato; diferentemente dos atos infracionais dos adultos que, muitas vezes, apresentam um planejamento pré-definido. $\mathrm{O}$ ato infracional do adolescente poderia ser entendido como uma transgressão às normas e aos valores sociais, à medida que o jovem não se percebe inserido na sociedade. A dita "emoção" seria, portanto, a busca de uma satisfação que compense a dor vivida na percepção de tal exclusão.

Roman (2009) aponta que os adolescentes entrevistados por ele mencionam uma sensação de "adrenalina", uma busca de uma excitação prazerosa, envolvendo-se em situações perigosas. $\mathrm{O}$ autor argumenta que, assim, eles intensificam o sentimento de estar vivo, proporcionando-lhes sensação de realização e preenchimento de um vazio pro- veniente de situações de humilhações.

O sujeito necessita de ser reconhecido. Quando isso não ocorre, ele pode buscar outras vias de reconhecimento, inclusive aquelas consideradas à margem da lei. De qualquer forma, não existem sujeitos excluídos, ninguém está totalmente fora da sociedade. Porém, existem sujeitos que permanecem efetivamente dentro das fronteiras da convivência, participando e criando estratégias de sobrevivência, seja aderindo passivamente à lógica excludente, seja agindo no sentido de transgredir/influenciar e/ou alterar as regras do jogo.

\section{Método}

A presente pesquisa é de natureza qualitativa. Esse tipo de abordagem caracteriza-se por seu aspecto compreensivo e interpretativo, trabalhando com a vivência, a experiência, as crenças e os valores dos sujeitos (ALVES-MAZZOTTI E GEWANDSZNAJDER, 1999). Entende-se que a epistemologia qualitativa baseia-se na recusa da neutralidade do pesquisador, sendo a própria relação pesquisador-pesquisado elemento constitutivo da pesquisa (GOLDENBERG, 2005). Essa recusa à neutralidade significa que o pesquisador se torna coparticipante da pesquisa, considerando seus resultados como cocriações e não como descobertas (BRITO, 2006).

Pretende-se aqui investigar os fatores relacionados à reinternação do adolescente ao CIAJ, mas do ponto de vista do próprio jovem. O intuito é apreender as versões dele, a partir do relato das suas vivências e experiências.

Como sujeitos de pesquisa, buscam-se adolescentes que cumpram medida socioeducativa de internação do CIAJ, indicados pela instituição, que sejam exemplares e representativos quanto à questão da reinternação. A exemplaridade e a representatividade foram definidas pela instituição. $\mathrm{O}$ diretor da instituição possuía, em seus 
arquivos, um registro com o número de reinternações de cada adolescente. Dessa forma, a direção da instituição indicou os adolescentes que cumprem medida pela segunda, terceira ou quarta vez. Portanto, entrevistaram-se adolescentes que cumprem medida, no mínimo, pela segunda vez.

Para a coleta de dados, foram utilizadas entrevistas semiestruturadas com 07 (sete) adolescentes internos do CIAJ. Para a limitação do número de entrevistados, adotou-se o critério de saturação dos dados, quando foi constatado que as entrevistas não traziam novos padrões (GOLDENBERG, 2005). As entrevistas foram realizadas nas dependências do CIAJ com devida orientação da coordenação sobre o local mais adequado. $\mathrm{O}$ material foi gravado em áudio, e um termo de consentimento livre e esclarecido foi assinado pelos responsáveis. Da mesma forma, os adolescentes foram consultados sobre a disponibilidade em participar da entrevista. A referência para que fossem abordados os temas nas entrevistas foi, principalmente, a vida do adolescente após a sua saída da instituição. Têm-se, como focos, a investigação das dificuldades vividas, a relação com os familiares e amigos após o cumprimento da medida, as perspectivas para o futuro. As entrevistas foram realizadas entre março e dezembro de 2010.

Adotou-se outro método para auxiliar na apreensão da realidade dos adolescentes, a observação participante. Tal método consiste na participação do pesquisador no cotidiano de um grupo ou organização, em contato direto com os observados, permitindo ao investigador científico captar dados e comportamentos/relações com/no meio. Assim, definimos observação participante como um processo no qual a presença do observador numa situação social é mantida para fins de investigação, em que o observador está em relação com os observados, participando com eles do ambiente relacionado ao campo pesqui- sado, no qual o observador ao mesmo tempo modifica e é modificado por esse contexto (Becker, 1994). Os pesquisadores se envolveram no cotidiano do CIAJ através de um estágio em psicologia realizado entre agosto e dezembro de 2010. Estas informações coletadas enriqueceram a análise das entrevistas.

Os dados coletados foram considerados através da análise de conteúdo, cujo objetivo é produzir inferências baseadas no referencial teórico, a partir de um tema ou uma palavra. Realiza-se a análise do conteúdo do material contido nas entrevistas, buscando-se o sentido explícito e implícito dos textos (Bardin, 1977). A análise do conteúdo latente é essencial ao método de análise de conteúdo, pois é a tentativa de compreensão do material latente, que permite a interpretação e a contextualização do tema em estudo, garantindo relevância. Foram construídas categorias que representam temas centrais nas falas dos adolescentes, em relação à reinternação. Para a identificação, utilizaramse somente letras maiúsculas a fim de preservar a identidade dos adolescentes. Desta forma, têm-se os sujeitos A1, A2, A3, A4, A5, A6 e A7.

Finalmente, é importante destacar que a pesquisa foi submetida ao Comitê de Etica em Pesquisa da Universidade Federal de Goiás (CEP/UFG), conforme Resolução 196/96 do Conselho Nacional de Saúde - Ministério da Saúde, e foi aprovada sob o número 033/2010.

\section{Resultados e discussão}

5.1 Rede de relacionamentos: família e amigos

Nesta categoria, interessa em perceber de que maneira o adolescente retrata as suas relações familiares e de amizade. De um modo geral, os adolescentes apontam as relações familiares de uma maneira positiva. Nem sempre 
eles têm uma relação próxima com os pais, mas existem outras figuras familiares importantes, como tias e avós.

Existe, no senso comum e até mesmo no discurso jurídico, a imagem de que o adolescente em conflito com a lei é proveniente de uma família "desestruturada". Muitas vezes, esse termo não é definido por quem o proclama. Parece que subjacente a tal discurso, está a culpabilização da família, como responsável pelo cometimento dos atos infracionais. Nesta pesquisa, não se sabia de antemão como a família seria retratada. No discurso dos adolescentes, esta é descrita como uma fonte de apoio emocional, de presença constante. Nos relatos, também aparece, por vezes, algum familiar com a função de colocar os limites e regras e dar "conselho".

E: E sua mãe, como é a relação de vocês?

A3: Ela sempre dá conselho, né. Essa segunda vez aqui, ela sempre me falou: "Pára de rolo, caça um serviço", e eu não dava ouvido. Todo dia, ela fala isso, e teve um dia ainda que eu peguei e falei: "moço, será que ela não cansa, ela está repetindo a mesma coisa".

E: E como é a relação com sua mãe? A5: Sempre foi boa a relação com a minha mãe. A única pessoa que mais me apoiou foi minha mãe.Ela não deixava sair com os amigos meus. Se eu saía com um colega diferente, ela já me prendia.

Ao contrário do que se pensa geralmente, os adolescentes entrevistados têm figuras familiares que dão suporte e que tentam fornecer algumas orientações. Estes "conselhos" não tinham uma influência decisiva na conduta dos adolescentes, que cometiam os atos infracionais mesmo tendo sido orientados em contrário. No entanto, a imagem de abandono e de famílias caóticas não foi confirmada pelos relatos dos jovens. As relações familiares podem ter um papel importante no cometimento dos atos infracionais, mas parece questionável colocá-la como fator causal preponderante.

Neste ponto, é importante se assinalar a concepção de adolescência adotada. Discorda-se do entendimento de que a adolescência seria um período natural de desenvolvimento. Outrossim, seria o resultado de uma construção histórica e social forjada nas sociedades capitalistas (OZELLA, 2002). As inovações tecnológicas no mundo do trabalho passaram a exigir uma extensão do tempo de formação. O desemprego estrutural da sociedade capitalista fomentou a necessidade de retardar a entrada dos jovens no mercado de trabalho. Sendo assim, houve um processo no qual a criança passou a ficar mais tempo sob a tutela dos pais. Portanto, entende-se como adolescência este período de latência social construída pela sociedade capitalista (OZELLA, 2002). Este período de afastamento do mundo do trabalho e de preparo para a vida adulta é uma construção social e traz, como uma de suas consequências, a aproximação do adolescente com um grupo de iguais.

Agora sejam observados alguns aspectos das relações de amizade dos adolescentes. Este aspecto é colocado por eles como um fator que influenciou fortemente o cometimento de atos infracionais:

A1: Ah, depois que eu saí do CIAJ a primeira vez, foi estranho. Os meus colegas eram todos mais certos. Eu vim preso, e as mães deles falaram alguma coisa pra eles, e eles pararam de andar comigo. Eu fui mudando as amizades. Eu mudei os colegas e eu comecei a ficar diferente. Comecei a fumar cigarro, essas coisas.

E: Você gosta da companhia desses amigos?

A1: Gostar eu não gosto, né... Mas eu gosto e não gosto... Mas eles vêm na porta, né... Porque eu nunca tive um amigo pra chegar lá em casa e falar assim: Oh, vamos pra igreja hoje, vai ter uma missa lá. Meus amigos sem- 
pre foi assim: Vamos ali, vai ter uma festa ali hoje. Só isso.

Os adolescentes colocam as amizades como um importante fator de risco para o cometimento de atos infracionais. Pode-se questionar se estes jovens estariam reproduzindo um discurso dos adultos sobre a influência das "más companhias" ou se estariam se eximindo de assumir a responsabilidade pelos conflitos com a lei. Outro aspecto a ser sublinhado é que a inserção em grupos é muito importante para a constituição da identidade do adolescente (DAYRELL, 2003). Pode ser que as três hipóteses anteriores contribuam para o problema, ou seja, o jovem repete um discurso dos adultos, na medida em que a imagem da juventude é formada na relação com os adultos (DAYRELL, 2003). Os adolescentes podem ter dificuldades em assumir a responsabilidade pelos seus atos, como aparece na fala de A1, os amigos o chamavam para a festa e não para igreja. A2 também coloca que ele "acabou" se envolvendo com furtos e drogas. Dessa forma, parece que esses adolescentes não tinham escolha a não ser obedecer aos ditames do grupo de amigos. A necessidade dos adolescentes de serem aceitos e reconhecidos pelo grupo de iguais é algo bastante imperiosa (SPAGNOL, 2005). Um questionamento se impõe: por que eles se inserem em grupos de adolescentes transgressores e não em outros tipos de grupos? $\mathrm{O}$ que eles buscariam nesses grupos além do reconhecimento e da aceitação? Pode ser que, nos grupos nos quais a transgressão está mais presente, os adolescentes tenham mais espaço para se comportarem de acordo com a lógica da virilidade (CARRETEIRO, 2003). De acordo com essa lógica, o jovem se comporta de modo destemido, corajoso e até violento, como forma de lidar com humilhações sofridas. Tratar-se-á mais adiante deste tema, no item "Lógica da virilidade e transgressão”.

\section{Expectativas para o futuro}

No roteiro de entrevista, foi elaborada uma questão na qual seria investigada quais expectativas o adolescente tem para o futuro. $\mathrm{O}$ intuito era tentar perceber se o jovem vislumbrava mudanças em sua identidade e seu estilo de vida.

No caso do A1, o futuro reservaria possibilidades de mudança desde que ele mudasse de cidade, pois, em Jataí, todos o enxergam como uma pessoa transgressora. Ele se percebe como refém do modo como os outros o veem.

E: E qual a sua expectativa quando você sair daqui?

A1: Mudar daqui. Eu tava querendo levar a minha namorada comigo, que ela quer ir embora comigo daqui. Ela não quer que eu fique aqui. Tentar viver em outra cidade. Só que sem fazer rolo, arrumar um serviço, trabalhar. Trabalhar e fazer o máximo pra não fazer bagunça, né! Pras pessoas não me verem do jeito que as pessoas me veem aqui. Aqui em Jataí eles me veem como um traficante.

E: Nessa outra cidade, você quer ser reconhecido como?

A1: Ah, sei lá. Uma pessoa diferente. Aquele cara lá é gente boa, ele é honesto. Ele devia aqui uma conta, ele nem esperou dar o prazo. Ele pagou ela já. Ele achou a minha carteira, ele me entregou. Ele viu um ladrão pulando lá no meu quintal, falou quem era.

Esse adolescente coloca o desejo de experimentar a identidade de ser honesto e de ser reconhecido desta forma. Coloca a questão do trabalho como uma forma de sair da criminalidade. No geral, os jovens apontaram o trabalho como alternativa para se construir uma vida sem transgressões. Percebese como um grande desafio o trabalho formal se tornar mais atraente do que enriquecimento fácil e rápido proporcionado pelo tráfico de drogas. Sem qualificação e formação, somente subempregos e trabalhos pouco atraentes 
esperam os jovens de periferia. As falas dos adolescentes demonstram a necessidade urgente da elaboração de políticas públicas de formação e de geração de emprego e renda para este público. $\mathrm{O}$ adolescente que não é assistido desta forma pode acabar tendo que ser punido pelo Estado posteriormente.

Quando perguntado sobre possibilidades de remuneração alternativas ao tráfico de drogas, o jovem A5 responde:

A5: Uai, não sei, não. Eu acho que agora é tarde. Porque já tô com dezoito anos, na sexta série. Eu penso em ir pra fazenda e ficar tranquilo, ficar sossegado.

E: Mas você acha que não tem possibilidade por que motivo?

A5: Porque é difícil demais arrumar emprego.

Zappe e Ramos (2010) definem o adolescente em conflito com a lei como aquele que busca sua inclusão na sociedade, que não tendo acesso aos bens de consumo ou outras formas de reconhecimento social, recorre à criminalidade. Os autores apontam que a maioria dos atos infracionais são crimes contra o patrimônio. $\mathrm{O}$ mundo contemporâneo dita padrões de felicidade e realização associados ao consumo e à busca imediata de prazer (BAUMAN, 2004). Parte-se do pressuposto de que a adolescência é um processo em que o adolescente é instado a construir um projeto de vida e uma identidade (MARTINS et al., 2003). Logo, o jovem percebe que, para ser reconhecido socialmente, ele deve estar inserido no mundo consumista. Os atos infracionais podem ser a via de acesso para a obtenção de sensações prazerosas e de bens de consumo. Tornam-se dramáticos os casos dos adolescentes de classes populares que veem o futuro como campo nulo de possibilidades. A escolarização, que poderia proporcionar uma formação para a inserção profissional, está esvaziada de sentido. O mundo da escola está em oposição ao desejo de prazer imediato, pois os resultados obtidos nos estudos não são percebidos em curto prazo (ZAPPE E RAMOS, 2010).

De que maneira a sociedade pode se envolver com a temática e oferecer melhores oportunidades de inserção social para estes jovens? No momento, essa é uma pergunta que merece consideração, mesmo sendo desconhecidos os caminhos para respondê-la.

No trecho abaixo, o adolescente A2 traça seu futuro, tendo como norteadores a construção de uma família e o exercício do trabalho:

E: Se você pudesse se ver daqui há cinco anos, como é que você acha que vai estar sua vida?

A2: A minha vida daqui há cinco anos!? Nossa senhora, eu vou ter minha casa, trabalhar com meu pai. Ter minha casa, vou ter um trem bom pra mim andar. Uma mulher também pra mim. E daqui há uns quinze anos, eu quero ter um filho.

\section{Internação e reinternação}

A análise desta categoria faz-se com base no discurso trazido pelos adolescentes quanto à permanência na instituição. Cabe a ressalva de que eles não trouxeram reflexões quanto ao cumprimento da medida socioeducativa e nem mesmo em relação à função desta. Neste caso, interessa saber quais os significados que os adolescentes atribuem ao aprisionamento.

Em algumas falas, os adolescentes colocam o período de internação como um espaço de aprendizado de novas habilidades quanto ao cometimento de atos infracionais, além de uma oportunidade de formarem grupos criminosos para atuarem após o cumprimento da medida, como se percebe nos trechos:

(...) Aqui no CIAJ cê só aprende coisa ruim.

Por exemplo, eu chego aqui, eu falo: moço, eu pegava uma droga ali com 
um cara ali. Moço, a droga era assim, assim e assim. Aí, o outro já fala: moço, pára de pegar com aquele lá, pega com o outro ali. A dele é melhor. Aí, eu falo: moço, eu comprava uns revólver assim, assim. O outro já fala: moço, eu sei onde tem um lugar melhor, baratim. Aí, um vai passando conhecimento um pro outro. Só aumenta o crime (A1).

Segundo Roman (2009), o foco socioeducativo que as instituições de internações para adolescentes em conflito com a lei deveriam possuir ainda não foi solidificado. Ao contrário, não houve a superação do caráter correcional e repressivo que as antigas instituições apresentavam. Isso dificulta a aplicação das medidas e caracteriza o seu tratamento para com o público alvo como punitivo e de "cura" para o sintoma-infração. Com isso, os jovens não atribuem um significado de ressocialização, pretendido pelas medidas socioeducativas, o que leva a esvaziar de sentido a função educativa, restringindo-se a um viés punitivo e de aprisionamento. De fato, algumas situações foram relatadas pelos adolescentes, nas quais podem existir sanções supostamente educativas, mas que são percebidas como punições pelos adolescentes, como no trecho a seguir:

E: Você ficou de castigo aqui por alguma coisa?

A1: Foi. Sem colchão, sem coberta, sem nada. Dormindo só na pedra lá.

E: Quantos dias?

A1: Ixii, foi mais de mês! Só me entregavam o colchão dez horas da noite. Era ruim!

Por outro lado, alguns adolescentes relataram que o período de internação pode representar uma oportunidade de reflexão sobre possíveis mudanças e reformulações de estilo de vida, conforme se segue:

A1: Ah, um dia eu parei e pensei: moço, os meninos tá tudo saindo, assistindo televisão. Todo mundo saindo pras atividade, jogando pimbolim e eu tô aqui trancado, aqui. (...) De hoje em diante, eu vou parar de ser besta! Peguei, comecei a lê a bíblia. Até hoje eu tô lendo ela. Já tô terminando de lê ela toda já. Parei de gritar, falei que nunca mais ia gritar o nome do diretor. Aí, eu também não sei esperar, sabe? Eu fico nervoso demais, fico nervoso memo. E, se não for na hora, pra mim não serve.

Neste caso, o adolescente tinha permanecido no "castigo", que é um alojamento individual. Não se pode precisar se ele alterou o discurso somente em função da punição sofrida ou se realmente seria uma mudança duradoura.

De acordo com o ECA (1990), as instituições de ressocialização devem ser reguladas por um paradigma socioeducativo e não punitivo. Na fala dos adolescentes, o que se percebe é que persiste, ainda, o caráter prisional e repressor das intervenções junto ao jovem que comete ato infracional.

A segregação e o isolamento do adolescente, apresentados no trecho acima, talvez não almejem a intenção educativa, conforme apontam Castro e Guareschi (2008). Para os autores, a internação aniquila a singularidade do adolescente, fato que foi possível observar nas interações dos funcionários do CIAJ com os adolescentes. Alguns funcionários comentavam que os adolescentes não têm recuperação, que não valia a pena investir esforços nesse sentido.

Pode-se notar os efeitos da institucionalização quando presenciada uma fala de A3, no qual dizia do seu medo de enlouquecer dentro do CIAJ. É importante sublinhar que esse medo é algo constante nas falas dos adolescentes. O processo de estar "perdendo a noção das coisas" foi relatado por dois deles durante a observação participante feita pelos pesquisadores. Além disso, relataram sentirem constantemente dores de cabeça, sensações de raiva e ódio in- 
tensos e crises de choro. Eles relataram duas situações que desencadeavam mal -estar: quando os educadores não atendiam alguns de seus pedidos, e quando pensavam na vida que tinham antes de entrar na instituição.

Outro grande obstáculo observado para a ressocialização dos adolescentes é o fato de que eles não recebem nenhum acompanhamento psicossocial após a saída da instituição. Dessa forma, todo o contexto em que vivia o adolescente permanece relativamente igual, sem intervenções.

\subsection{Lógica da virilidade e transgressão}

Esta categoria foi formulada com base na ideia de Carreteiro (2003), de que os sujeitos podem utilizar da lógica da virilidade como forma de reação diante de humilhações e falta de reconhecimento. Estes sofrimentos sociais, como aponta a autora, não recebem um espaço para serem expressos. Os adolescentes passam a agir de forma destemida, corajosa e, por vezes, até violenta, chegando, então, a transgredir a lei, como uma maneira de reagir frente às humilhações.

Retomam-se aqui as ideias de Welzer-Lang (2001) de que a socialização masculina prepara os homens para serem autores de violência. $\mathrm{O}$ pequeno homem - criança e adolescente - submete-se às violências dos mais velhos para alcançar o status de verdadeiro homem. A dor decorrente das violências físicas e psicológicas não pode ser expressa. Posteriormente, o jovem homem passa a ser violento nas suas relações com outros homens e com mulheres, acabando por transgredir a lei.

Durante a observação participante, em conversas com os adolescentes, foi relatado por eles que a entrada no mundo da criminalidade ocorre por três motivos: fama, dinheiro e respeito. Ser famoso, possuir dinheiro e ser respeitado significa, para esses indivíduos, ser reconhecido e, ao mesmo tempo, temi- do pela sociedade. Talvez o ser temido seja equiparado a ser reconhecido. Sem perspectivas futuras de inserção social, o jovem persegue esse reconhecimento através dos atos infracionais. Como aponta Welzer-Lang (2001), "exorcizar o medo agredindo o outro e gozar dos benefícios do poder sobre o outro" (p. 464) transforma-se no lema de vida destes adolescentes em conflito com a lei, em que ninguém jamais irá conseguir fazê-los passar por qualquer humilhação e sofrimento.

Transgredir a lei passa a ser a maneira adotada para se mostrarem como jovens homens viris, detentores de poder e coragem, como é ilustrado no trecho a baixo:

(...) Ficava zuando lá na rua. Fazendo zueira, doido na rua. Todo dia, eu estava no frevo, todo dia. Aí, eles comentavam sempre alguma coisa. Quando a polícia chegava, eles falavam: nossa, você é doido, hein cara. Eu ficava muito viajando. Eu fui uma vez pra Bolívia também de moto. (A1)

Ser reconhecido como "doido" pelos policiais e relatar que praticou viagens longas é, para esse adolescente, mostrar sua virilidade, mostrar que é capaz de realizar atos dignos de reconhecimento. Possuir a identidade de "doido" é receber o reconhecimento de que se é diferente dos demais e, concomitantemente, sair da invisibilidade.

A ideia de Spagnol (2005), de que a desigualdade social e o estímulo ao consumismo podem possuir uma parcela de responsabilidade para a execução de atos infracionais entre os adolescentes, pode ser muito bem encaixada dentro das situações relatadas pelos adolescentes nas entrevistas. Levando-se em consideração que o tráfico está presente na maioria dos casos dos adolescentes entrevistados, esta seria uma maneira rápida e fácil enriquecimento. Com o intuito de manter o poder 
conquistado com o enriquecimento e de se defender de possíveis humilhações, o adolescente acaba utilizando da lógica da virilidade descrita por Carreteiro (2003), conforme se pode perceber na seguinte fala:

(...) Aí, eu fui com o revolver e cheguei na frente dele pra não dar o tiro nas costas e falei: e aí cara, você não vai me pagar, não? Aí, ele falou: rapaz, você fica de boa aí, porque se não eu não vou te pagar, não. Ah, quer saber eu não vou te pagar é nada. Ele falou isso na hora que eu estava grilado, e eu pensei assim: só porque eu sou pequeno ele não vai nem me pagar. Não vai nem conversar comigo e está conversando com esse outro cara que é praticamente mais novo nesse ramo que eu. Não está acontecendo isso, não. Vai pagar ele e não vai me pagar só por que eu sou pequeno. Ah, mas eu grilei na hora e dei um tiro na boca dele. Aí ele veio pra vir em mim e saiu correndo. Aí, ele foi e caiu no chão. E eu fui lá e dei mais três tiros na cara dele. (A7)

Nessas falas acima, pode-se perceber que reagir de forma violenta seria a única forma de recuperar ou manter $\mathrm{o}$ respeito. $\mathrm{O}$ adolescente $\mathrm{A} 7$ demonstra que sente certo orgulho de poder possuir várias armas que são o veículo de sua vingança frente a humilhações vindas dos outros. Quando alguém não cumpre o combinado, ele fica "grilado", talvez se sentindo ultrajado e inferiorizado. A saída percebida por ele é agir de forma cruel na demonstração de que os atos viris substituem quaisquer possibilidades de negociação. Quando o irmão pergunta se ele recuperou o dinheiro, e ele toma a decisão de agir violentamente, pode-se notar que o olhar do outro tem um grande peso na execução dos atos viris. Dar uma resposta ao outro de que se é destemido, corajoso e perigoso, conseguindo, enfim, entrar para a "casa dos homens" descrita por Welzer-Lang (2001) é um meio de expurgar senti- mentos de vergonha e humilhação.

\section{Considerações finais}

Após a realização de entrevistas e de observações no contexto de uma instituição de adolescentes cumprindo medidas socioeducativas, foi possível perceber alguns aspectos. A expectativa de que eles fossem relatar um quadro com relações familiares caóticas e abandono de figuras parentais foi quebrada. Pelo contrário, os jovens trouxeram, em seus relatos, alguma figura familiar importante. Esta tentava "dar conselhos", que não foram ouvidos pelos adolescentes. Portanto, a visão bastante difundida de que a família "desestruturada" é a causa preponderante no cometimento de delitos, parece questionável. Diferentemente da família, as relações de amizade foram colocadas como tendo um papel decisivo no cometimento dos atos infracionais. Os adolescentes foram "levados" pelos amigos e companheiros a se envolverem em delitos, o que demonstra a força do grupo de iguais para os adolescentes, além de uma tentativa de negar a responsabilidade pelos atos. Além disso, os grupos buscados são os de adolescentes que também cometem transgressões. A hipótese deste trabalho é a de que esses grupos são mais atraentes, porque neles os adolescentes podem exercer a lógica da virilidade, que é uma maneira de expurgar os sentimentos de vergonha através da violência (CARRETEIRO, 2003). Os adolescentes sentem que é necessário serem viris porque a força e a violência são importantes em ambientes hostis, como o universo do tráfico de drogas, por exemplo.

$\mathrm{O}$ futuro é percebido sob duas óticas contrárias. Ora é visto como um campo de possibilidades de reinvenção de uma nova identidade, longe dos atos infracionais, e para que isso ocorra, o trabalho é visto como uma possível saída; ora, a ausência de boas perspectivas de trabalhos dignos, leva os adolescen- 
tes a perceberem o futuro ausente de possibilidades de não se recorrer a uma vida de crimes.

A internação e a consequente institucionalização não trazem resultados favoráveis. O convívio com outros adolescentes em conflito com a lei pode representar um espaço de aprendizagem de novas habilidades ligadas a um estilo de vida de transgressão. $\mathrm{O}$ fato de que as instituições de internação possam funcionar como lugares de formação de quadrilha é muito grave. As instituições de internação precisam se tornar espaços diferenciados, não podem funcionar como as prisões de adultos, reproduzindo suas mazelas. Conforme foi sinalizado no início, as instituições de internação têm um caráter punitivo e repressor, em vez de serem um espaço educativo. A despeito do ECA, permanece, por parte do Estado, uma lógica menorista que tutela e pune os jovens vistos como delinquentes. $\mathrm{O}$ presente trabalho pode contribuir para que se reveja a lógica presente nas instituições de internação. Além do respeito à singularidade do adolescente, devem ser oferecidos espaços de reflexão em grupo e possibilidades de emprego e renda na saída da instituição.

$\mathrm{O}$ adolescente pode entrar em conflito com a lei como forma de obtenção de reconhecimento, de saída de uma invisibilidade e de se mostrar viril, exorcizando uma imagem de fraqueza, como percebido nos relatos. A violência que busca a "adrenalina", permitindo que o adolescente saia de uma sensação de vazio e se sinta vivo. O que se percebe é que os adolescentes não têm perspectivas de serem reconhecidos socialmente. Há poucas possibilidades de desenvolvimento de suas habilidades e de terem uma maior valorização social, especialmente os jovens de periferia. A normatização contemporânea da valorização da capacidade de consumismo como forma de construção identitária parece colocar os adolescentes na possibilidade de ruptura de quaisquer contratos sociais. O sofrimento ético-polí- tico decorrente das humilhações sociais pode fomentar o exercício da violência como reconhecimento social. Parece questionável o termo utilizado frequentemente quando se pensa em adolescentes em conflito com a lei: ressocialização. Como ressocializar se ainda não houve uma inclusão?

Parece urgente o planejamento de políticas públicas pensadas pelo Estado e pela sociedade civil com o foco nos adolescentes que se encontram em um processo de latência social, no qual a busca pela identidade é muito importante. O problema do jovem em conflito com a lei é de toda a sociedade. Não parecem razoáveis propostas como o rebaixamento da idade penal, na medida em que não são soluções punitivas e repressoras a melhor maneira de se resolver a questão. Talvez seja improvável que as intervenções com os adolescentes em conflito com a lei sejam bem sucedidas se não for construída uma rede na qual sociedade, setor judiciário e governo articulem conjuntamente as suas ações. O interessante é oferecer boas condições de educação e perspectivas interessantes de emprego e renda para que o adolescente sinta que participa realmente das trocas sociais. Dessa forma, não será necessário que o Estado exclua e castigue os adolescentes.

\section{Referências}

ALVES-MAZZOTTI, Alda e GEWANDSZNAJDER, Fernando. O método nas ciências naturais e sociais: pesquisa quantitativa e qualitativa. São Paulo: Thompson, 1999.

BARDIN, Laurence. Análise do Conteúdo. Lisboa: Edições 70, 1977. BAUMAN, Zygmunt. Amor Líquido. Rio de Janeiro: Jorge Zahar, 2004.

BECKER, Howards. Métodos de pesquisa em ciências sociais. São Paulo: Hucitec, 1994. 
BRITO, Valéria. Um convite à pesquisa: epistemologia qualitativa e psicodrama. IN: MONTEIRO, André. Pesquisa Qualitativa e Psicodrama. São Paulo: Ágora, 2006, cap. 1, p. 15-56.

CARRETEIRO, Teresa Cristina. Sofrimentos Sociais em Debate. Psicologia USP, vol. 14, n. 03, p. 5772, 2003.

CASTRO, Ana Luiza Souza e GUARESCHI, Pedrinho. Da privação da dignidade social à privação da liberdade individual. Psicologia \& Sociedade, vol. 20, n. 2, p. 200-207, 2008.

DAYRELL, Juarez. O jovem como sujeito social. Revista Brasileira de Educação, vol. 24, n. 3, p. 40-52, 2003. ECA - Estatuto da Criança e do Adolescente - Lei $\mathrm{n}^{\circ}$ 8.069, de 13 de julho de 1990.

GOLDENBERG, Mirian. A arte de pesquisar. Rio de Janeiro: Record, 2005.

\section{SECRETARIA DE DIREITOS HUMANOS. Levantamento Nacional do Atendimento Socioeducativo ao adolescente em conflito com a Lei- 2009. Brasília, 2009. Disponível em: $<$ http://www.ilanud.org.br/midia/doc/ Levantamento-Nacional-SINASE- 2009-SDH-SNPDCA.PDF>. Acesso em: 15 set. 2012.}

MARTINS, Priscilla de Oliveira; TRINDADE, Zeidi Araújo; ALMEIDA, Ângela Maria de Oliveira. O ter e o ser: representações sociais da adolescência entre adolescentes de inserção urbana e rural. Psicologia: Reflexão e Crítica, vol. 16, n. 3, p. 555-568, 2003.

OZELLA, Sérgio. Adolescência: uma perspectiva crítica. In: Contini, Maria de Lourdes Jeffery (org.). Adolescência e Psicologia: concepções, práticas e reflexões críticas. Rio de Janeiro: Conselho Federal de Psicologia, 2002, cap. 1, p. 16-24.

Regimento Interno do CIAJ - Centro de Internação para Adolescentes de Jataí - GO e Regimento da Comissão de Disciplina. 2006

ROMAN, Marcelo Domingues. Psicologia e Adolescência Encarcerada: Embates de uma Atuação em Meio à Barbárie. São Paulo: Editora Unifesp, 2009.

SPAGNOL, Antônio Sérgio. Jovens delinquentes paulistanos. Tempo Social, vol. 17, n. 2, p. 275-29, 2005.

WELZER-LANG, Daniel. A construção do masculino: dominação das mulheres e homofobia. Estudos Feministas, vol. 9, n. 2, p. 460-482, 2001.

ZAPPE, Jana Gonçalves e RAMOS, Nara Vieira (2010). Perfil de adolescentes privados de liberdade em Santa Maria/RS. Psicologia \& Sociedade, vol. 22 , n. 2 , p. 365-373, 2010. 